Received: $14-\mathrm{VI}-2018$

Accepted: $27-\mathrm{VI}-2018$

Published Online: 4-VII-2018

\section{Complex-Compound Odontoma: A Rare Clinical Presentation}

\section{Odontoma compuesto complejo: Una presentación clínica rara}

Damla Torul DDS, PhD1; Metehan Keskin DDS2;

Seda Gun DDS, $\mathrm{PhD}^{3}$; Didem Odabasi DDS, $\mathrm{PhD}^{4}$

1. Department of Oral and Maxillofacial Surgery, Faculty of Dentistry, Ordu University, Ordu, Turkey.

2. Department of Oral and Maxillofacial Surgery, Faculty of Dentistry, Ondokuz Mayis University,

Samsun, Turkey.

3. Department of Pathology, Faculty of Medicine, Ondokuz Mayis University, Samsun, Turkey.

4. Department of Pedodontics, Faculty of Dentistry, Ordu University, Ordu, Turkey.

Correspondence to: Dr. Damla Torul - damlatorul@gmail.com

ABSTRACT: Odontomas can be detected as complex or compound variants and they rarely show the histologic characteristics of both types together. The tumor commonly associated with malocclusion, eruption disturbances and pathological anomalies, but they seldom cause bony expansion. Early detection and management of odontoma with multidisciplinary approach pose an important role to prevent disturbances associated with this common odontogenic tumor. Here we report a rare case of an odontoma which show the features of both complex and compound types and also cause bony expansion, eruption failure in an 8-year-old boy.

KEYWORDS: Odontoma; Hamartoma; Malocclusion; Tooth; Impacted; Bone; Expansion.

RESUMEN: Los odontomas pueden detectarse como variantes complejas o compuestas y rara vez muestran la característica histológica de ambos tipos juntos. El tumor comúnmente se asocia con maloclusión, alteraciones de la erupción y anomalías patológicas, pero rara vez causan expansión ósea. La detección temprana y el manejo del odontoma con abordaje multidisciplinario representan un papel importante para prevenir las alteraciones asociadas con este tumor odontogénico común. Aquí presentamos un caso raro de un odontoma que muestra las características de los tipos complejos y compuestos y también causa expansión ósea, falla de erupción en un niño de 8 años.

PALABRAS CLAVE: Odontoma; Hamartoma; Maloclusión; Diente; Impactado; Hueso; Expansión. 


\section{INTRODUCTION}

Odontoma is the most common benign odontogenic tumor which originate from the pathological development of dental tissues (1). Although odontomas are classified as toothforming neoplastic lesions, they rather considered as hamartomaus malformation or developmental anomaly (2). Regarding histological characteristics odontomas have compound and complex variants. While the compound odontoma is seen as rudimentary dental structures, complex odontoma is observed as an irregular mass of dental tissues $(3,4)$. However, odontomas rarely show the features of both complex-compound types together and this type of odontoma referred as complex-compound odontoma in the literature (5). The exact etiology of this pathology has not been clearly identified, but infection, trauma, family history, and genetic mutation are considered as the predisposing factors that contribute the occurrence of odontomas (4). Due to their asymptomatic nature, odontomas are detected incidentally on radiological examinations and are usually associated with an impacted tooth (1). In majority of the cases they located intraosseously in the jawbones (3). However, they can rarely cause clinically detectable expansion in the jawbones $(3,6,7)$.

In this paper, management of a rare case of complex-compound odontoma that cause bony expansion, and eruption failure of the right maxillary incisor teeth is presented.

\section{CASE REPORT}

An 8 year-old-girl was referred to our clinic due to the eruption failure of the right maxillary first and second incisor teeth and hard swelling at the gingiva of the right maxillary incisor region. Medical history of the patient was non-contributory and any history of trauma to the maxillofacial region was reported. Intraoral examination revealed that left maxillary first and second incisor permanent teeth, were perfectly formed, well arranged and erupted but the permanent right maxillary first and second incisor have not erupted yet. Also, there was a clinically detectable swelling in the right incisor region of the maxilla. The occlusal radiograph obtained at the first examination showed multiple radiopaque mass that was closely associated with the crown of the un-erupted first and second permanent incisor teeth of the right maxilla (Figure 1). Panoramic examination showed un-erupted right maxillary first incisor in the horizontal and second incisor in vertical position because of disturbance in the root and eruption position that occur with the effect of odontoma. Impacted teeth were seems to be well-developed but covered with multiple gross radiopaque masses (Figure 2). According to clinical and radiographical examinations, provisional diagnosis considered as odontoma. After the consultation was made with pediatric dentistry and orthodontics departments, the removal of the odontoma and follow up were decided, to see whether the impacted teeth were erupted after the removal of odontoma. Therefore, the removal of the mass under general anaesthesia was planned. After informed consent taken from the parents a full thickness mucoperiosteal flap was elevated buccally between the upper right canine to the left upper second incisor teeth. Bony expansion in the right incisor region of the maxilla viewed clearly (Figure 3). A thin lamina of the bone covering the vestibular surface was removed. There were a great number of tooth like structures and they were removed without disturbing the underlying permanent first and second upper right incisors (Figure 4). The flap was replaced and sutured with 4-0 silk sutures. The gross specimen consisted of multiple malformed tooth-like structures send to histopathological examination. Histologically, the sections revealed enamel, dentin, cementum and which were intermingled with pulp-like tissues in few areas. These structures were arranged regularly in few areas, whereas, in few areas it was haphazardly arranged (Figure 5). The postoperative period 
was uneventful (Figure 6). After mucosal healing the eruption of the impacted teeth to see if there will completed, a space maintainer was placed to follow be a requirement for further orthodontic treatment.

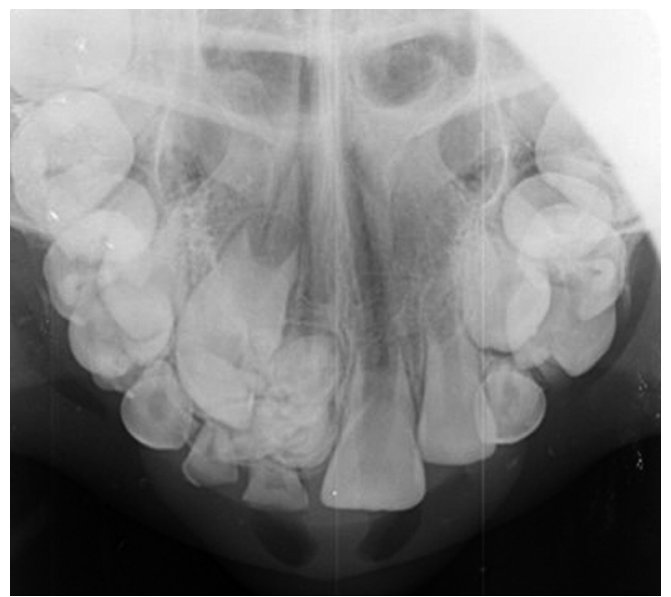

Figure 1: Preoperative occlusal radiography showing multiple radiopaque masses and impacted teeth.

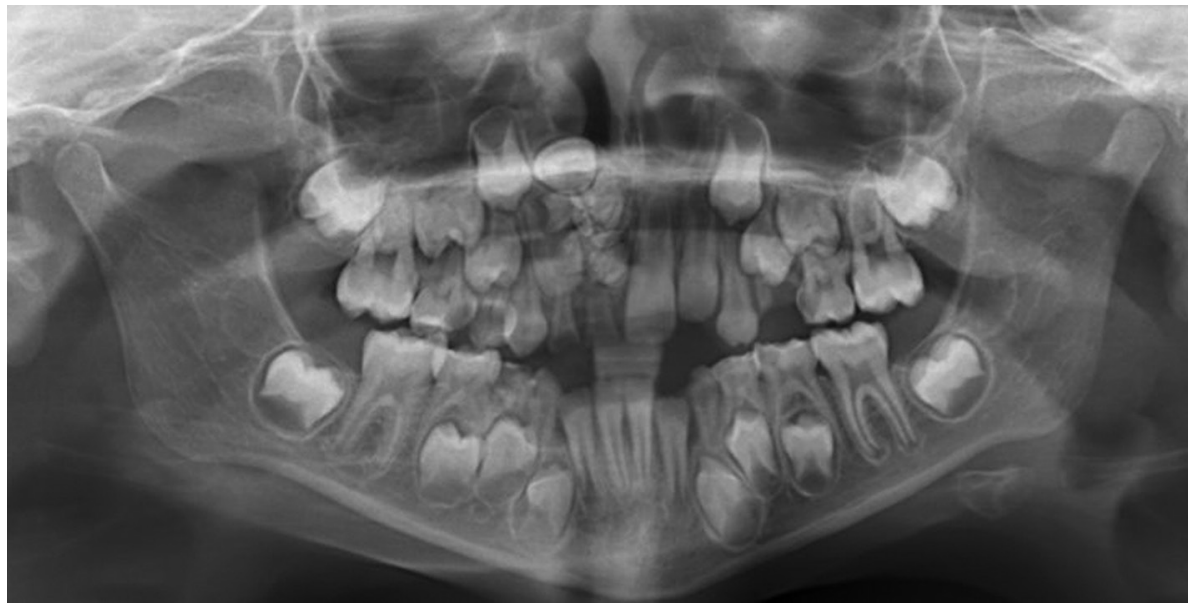

Figure 2: Panoramic radiography showing multiple radiopaque masses and impacted teeth.

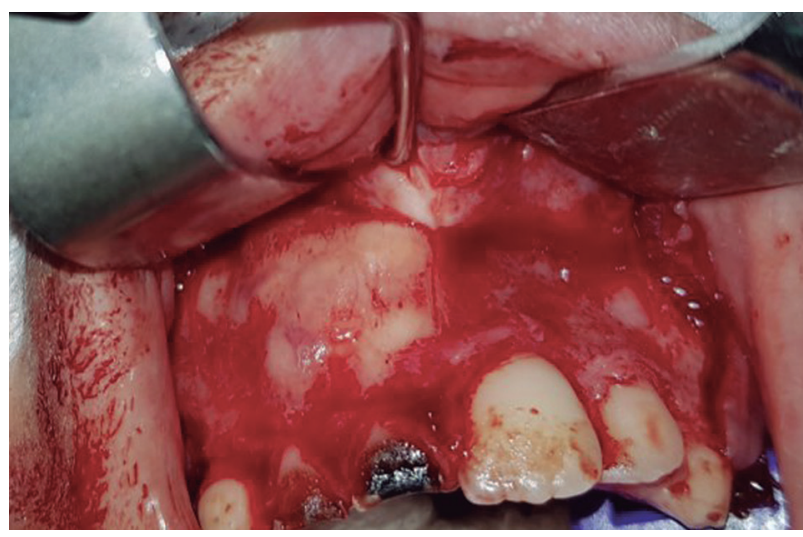

Figure 3: Intraoral photograph showing the bony expansion. 


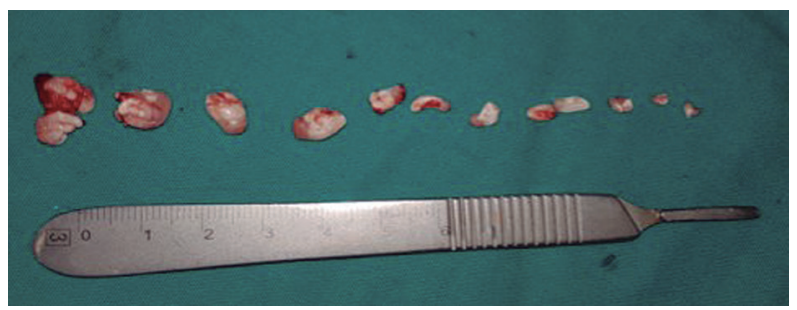

Figure 4: Excised specimen of complex-compound odontoma.

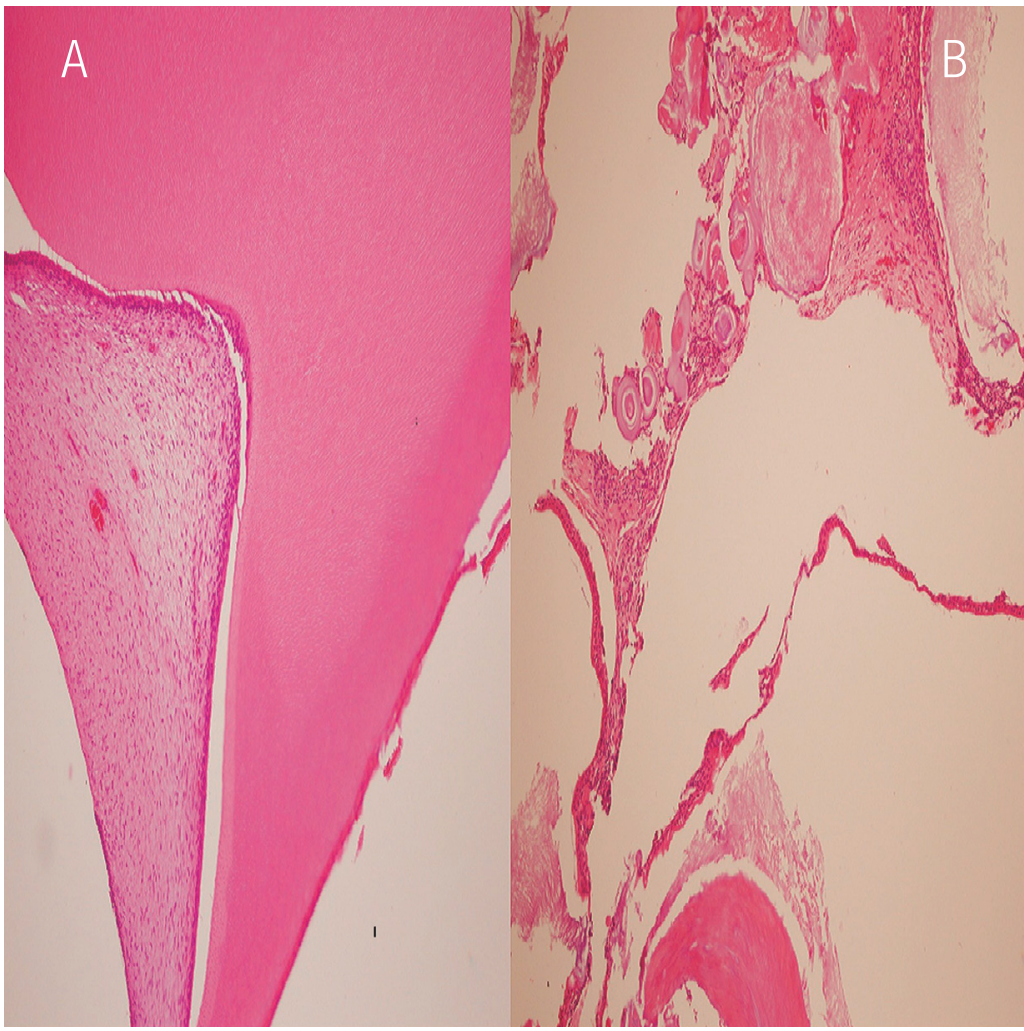

Figure 5: Compound odontoma have enamel, dentin, cementum and pulp tissue recapitulating normal teeth $(A)$, in contrast to the disorganized structure encountered in complex odontoma (B) (HEX200).

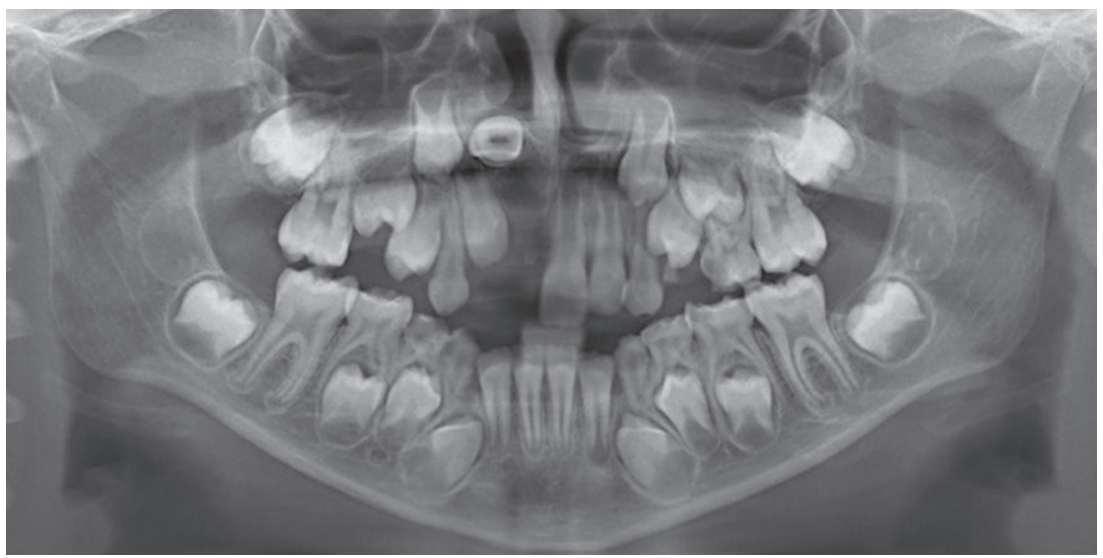

Figure 6: Postoperative radiograph. 


\section{DISCUSSION}

Odontomas are the most common odontogenic tumors constitute of $22 \%$ of all odontogenic tumors of the jaws (8). They are generally asymptomatic and detected incidentally on routine radiographic examinations in the second and third decades of life (9). Radiographically, odontomas present as well-defined radioopacities which surrounded by a radiolucent halo (8). The majority of compound type occur in the anterior maxillary region, whereas the great majority of complex type located in the posterior areas, especially in the mandible, without any gender predominance $(8,10)$. Although, odontoma is one of the most common tumor of the jaws, complex-compund type odontoma which shows both histologic features of compound and complex types is rarely seen. We can found only five reports (4 case report and 1 retrospective study) about the complex-compund odontoma in the English language literature (5,11-14). Thus, this report is valuable as it consists an interesting and rare presentation of this common tumor.

Clinically, odontomas grow slowly and have a non-aggressive characteristic. The most common associated symptoms with odontoma are pain, swelling, malocclusion and pathological anomalies observed in the neighboring teeth $(8,9,15)$. It is reported that $37-77 \%$ of eruption disorders is associated with odontomas (16). Consistent with what is reported in the literature in the present case odontoma cause eruption failure of two permanent incisor teeth.

Odontomas observed in most of the cases impacted within the jaw bones. Extraosseous position and eruption in the oral cavity rarely seen (3). Although odontomas are usually in the bone structures and do not show outward signs such as expansion of the bone, in the rare instances they can be examined visually and this phenomenon has extremely rare occurrence in the cases of compound odontomas $(1,17)$. In our case because of the detectable expansion of the bone that surround the complex-compound odontoma, it can be observed manually in clinical examination. The reason for this has been discussed in the literature previoulsly. However, the exact etiology is still controversial. It is considered that the eruption or expansion of the odontomas caused by the eruptive forces arise from the impacted teeth. Also, the reason attributed to the resorption of alveolar ridge, alveolar bone remodeling and growth of the capsule surrounding odontoma $(4,17)$. Treatment consists of removal of the lesion and curettage of the region to prevent the possibility of cystic degeneration (18).

\section{CONCLUSION}

Because of the complications such as impaction, malocclusion, caries, gingival inflammation may occur due to the presence of the odontoma, it is suggested that the management and follow-up of this cases should be done with multidisciplinary approach. In our case treatment and follow up of the patient was performed with the help of a pediatric dentist to prevent further disturbances caused by the odontoma. Also, the patient was referred to the orthodontics for treatment of impacted teeth after postoperative healing completed.

\section{REFERENCES}

1. Bordini J., Jr., Contar C. M., Sarot J. R., Fernandes A., Machado M. A. Multiple compound odontomas in the jaw: case report and analysis of the literature. J Oral Maxillofac Surg. 2008; 66 (12): 2617-20.

2. Mupparapu M., Singer S. R., Rinaggio J. Complex odontoma of unusual size involving 
the maxillary sinus: report of a case and review of CT and histopathologic features. Quintessence Int. 2004; 35 (8): 641-5.

3. Serra-Serra G., Berini-Aytes L., Gay-Escoda C. Erupted odontomas: a report of three cases and review of the literature. Med Oral Patol Oral Cir Bucal. 2009;14 (6): E299-303.

4. Arunkumar K. V., Vijaykumar, Garg N. Surgical management of an erupted complex odontoma occupying maxillary sinus. Ann Maxillofac Surg. 2012; 2 (1): 86-9.

5. Smith G. C. An interesting presentation of a complex-compound odontome. Aust Dent J. 1985; 30 (4): 265-7.

6. Junquera L., de Vicente J. C., Roig P., Olay S., Rodriguez-Recio O. Intraosseous odontoma erupted into the oral cavity: an unusual pathology. Med Oral Patol Oral Cir Bucal. 2005; 10 (3): 248-51.

7. Padmanabhan M. Y., Pandey R. K., Aparna R. Erupted composite odontoma associated with malformed teeth - unusual dental aberrations following maxillofacial trauma. Rom J Morphol Embryol. 2013; 54 (4): 1153-6.

8. Shekar S., Rao R. S., Gunasheela B., Supriya N. Erupted compound odontome. J Oral Maxillofac Pathol. 2009; 13 (1): 47-50.

9. Amado Cuesta S., Gargallo Albiol J., Berini Aytes L., Gay Escoda C. Review of 61 cases of odontoma. Presentation of an erupted complex odontoma. Med Oral. 2003; 8 (5): 366-73.

10. Tejasvi M. L.A., Babu B. B. Erupted compound odontomas: a case report. J Dent Res Dent Clin Dent Prospects. 2011; 5 (1): 33-6.
11. Soluk Tekkesin M., Pehlivan S., Olgac V., Aksakalli N., Alatli C. Clinical and histopathological investigation of odontomas: review of the literature and presentation of 160 cases. J Oral Maxillofac Surg. 2012; 70 (6): 1358-61.

12. Prabhakar C., Haldavnekar S., Hegde S. Compound-Complex odontoma-An important clinical entity. Journal of International Oral Health. 2012; 4 (1): 49-53.

13. Khanum N., Shivalingu M. M., Lingaraju N., Basappa S. Compound-complex odontoma: A case report of a rare variant. J Indian Acad Oral Med Radiol. 2014; 26: 463-6.

14. Samuels H. S., Gerry R. G. Complex-compound odontoma: report of case. J Oral Surg Anesth Hosp Dent Serv. 1963; 21: 348-52.

15. Verma S., Arul A. S., Arul A. S., Chitra S. Erupted complex odontoma of the posterior maxilla: A rarity. J Nat Sci Biol Med. 2015; 6 (Suppl 1): S167-9.

16. Ohtawa Y., Ichinohe S., Kimura E., Hashimoto S. Erupted complex odontoma delayed eruption of permanent molar. Bull Tokyo Dent Coll. 2013; 54 (4): 251-7.

17. Hanemann J. A., Oliveira D. T., Garcia N. G., Santos M. R., Pereira A. A. Peripheral compound odontoma erupting in the gingiva. Head Face Med. 2013; 9:15.

18. Amailuk P., Grubor D. Erupted compound odontoma: case report of a 15-year-old Sudanese boy with a history of traditional dental mutilation. Br. Dent J. 2008; 204 (1): 11-4. 